\title{
Night Life
}

\section{Red giant flying squirrel}

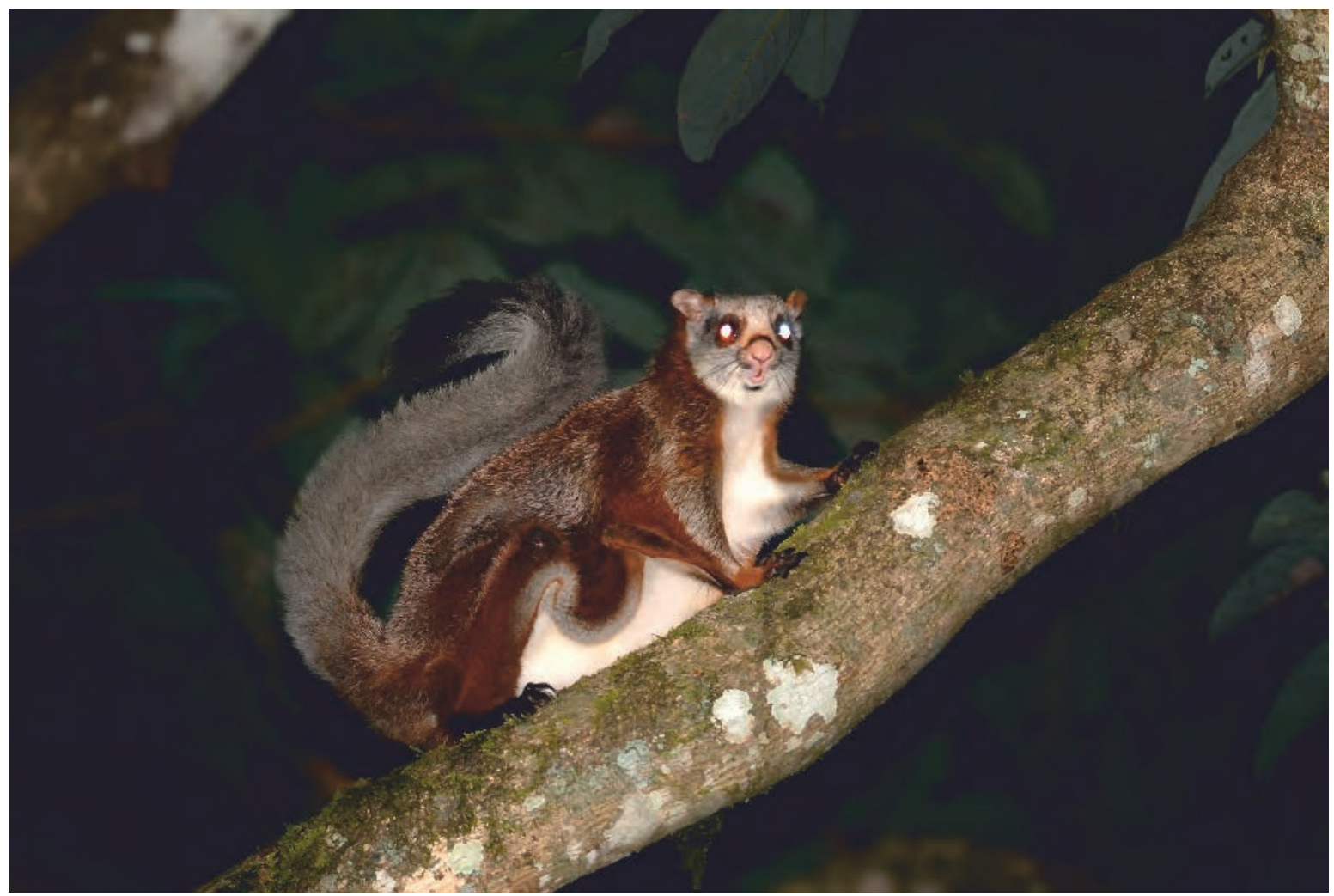

The red giant flying squirrel (Petaurista petaurista) has a broad geographic range in southeast Asia, from Afghanistan to Java, and Kashmir and southern China to Sri Lanka. It is among the largest flying squirrels, with a head and body length of $398 \mathrm{~mm}$ and body weight of $1750 \mathrm{~g}$. The fur colour of the species is typically reddish-brown above with light-coloured underparts, although this can vary depending on the location and the subspecies groups. Nocturnal and solitary, red flying squirrels feed on young leaves, shoots, flowers, fruits, nuts, seeds, lichen, moss, twigs and bark. The species is also known to include pine cones in its diet in the northern part of its range. They make their nests inside tree cavities. Like other flying squirrels, the red giant flying squirrel does not really fly, but glides from tree to tree. This gliding is made possible because of the patagium or the flying membrane that extends from the wrist to its hind legs and between the tail and the hind legs. Using the tail and hind limbs, flying squirrels can steer their glide path. Such glides are usually from the upper tree canopy to the lower or mid canopy and are about 50 metres long, although glides can also be as long as $450 \mathrm{~m}$. Although the species is relatively common within its geographic range, it is affected by habitat loss, due to deforestation and to a lesser extent, by hunting.

Photo credit: Kalyan Varma

Text credit: Sindhu Radhakrishna

Vol.26, No.6, DOI: https://doi.org/10.1007/s12045-021-1186-0 